\title{
Chlamydia trachomatis and Neisseria gonorrhoeae in HIV-infected Pregnant Women and Adverse Infant Outcomes
}

\author{
Kristina Adachi, MD, * Jeffrey D. Klausner, MD, MPH, *广 Jiahong Xu, MS, MPH, † Bonnie Ank, BA, * \\ Claire C. Bristow, PhD, MPH, MSc, † Mariza G. Morgado, PhD, $\S$ D. Heather Watts, MD, $₫$ Fred Weir, PhD, \| \\ David Persing, MD, PhD, \| Lynne M. Mofenson, MD, **Valdilea G. Veloso, MD, § Jose Henrique Pilotto, MD, †† \\ Esau Joao, MD, t+ Glenda Gray, MD, §§ Gerhard Theron, MD, $9 / 9$ Breno Santos, MD, || || Rosana Fonseca, MD, ***

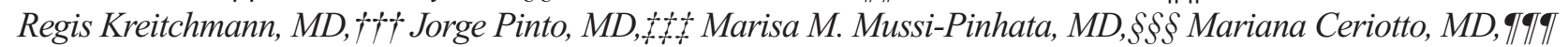 \\ Daisy Maria Machado, MD, || || || Yvonne J. Bryson, MD, * Beatriz Grinsztejn, MD, PhD, § Francisco I. Bastos, MD, PhD, $\S$ \\ George Siberry, MD, MPH, ** and Karin Nielsen-Saines, MD, MPH, * for the NICHD HPTN 040 Study Team
}

\begin{abstract}
Background: Sexually transmitted infections (STIs) in pregnancy such as Chlamydia trachomatis (CT) and Neisseria gonorrhoeae (NG) may lead to adverse infant outcomes.

Methods: Individual urine specimens from HIV-infected pregnant women diagnosed with HIV during labor were collected at the time of infant birth and tested by polymerase chain reaction for CT and NG. Infant HIV infection was determined at 3 months with morbidity/mortality assessed through 6 months.
\end{abstract}

Results: Of 1373 maternal urine samples, 277 (20.2\%) were positive for CT and/or NG; 249 (18.1\%) for CT, 63 (4.6\%) for NG and 35 (2.5\%) for both CT and NG. HIV infection was diagnosed in 117 (8.5\%) infants. Highest rates of adverse outcomes (sepsis, pneumonia, congenital syphilis, septic arthritis, conjunctivitis, low birth weight, preterm delivery and death) were noted in infants of women with CT and NG (23/35, 65.7\%) compared with NG (16/28, $57.1 \%)$, CT $(84 / 214,39.3 \%)$ and no STI $(405 / 1096,37 \%, P=0.001)$. Death
( $11.4 \%$ vs. $3 \%, P=0.02)$, low birth weight $(42.9 \%$ vs. $16.9 \%, P=0.001)$ and preterm delivery $(28.6 \%$ vs. $10.2 \%, P=0.008)$ were higher among infants of $\mathrm{CT}$ and NG-coinfected women. Infants who had any adverse outcome and were born to women with CT and/or NG were 3.5 times more likely to be HIV infected after controlling for maternal syphilis (odds ratio: $3.5,95 \%$ confidence interval: 1.4-8.3). By adjusted multivariate logistic regression, infants born to mothers with any $\mathrm{CT}$ and/or NG were 1.35 times more likely to have an adverse outcome (odds ratio, 1.35; 95\% confidence interval, 1.03-1.76). Conclusions: STIs in HIV-infected pregnant women are associated with adverse outcomes in HIV-exposed infected and uninfected infants.

Key Words: HIV, pregnancy, chlamydia, gonorrhea, sexually transmitted infections, adverse infant outcomes

(Pediatr Infect Dis J 2016;35:894-900)
Accepted for publication January 22, 2016

From the *David Geffen UCLA School of Medicine, Los Angeles, California; †UCLA Fielding School of Public Health, Department of Epidemiology, Los Angeles, California; † Westat, Rockville, Maryland; §Fundacao Oswaldo Cruz (FIOCRUZ), Rio de Janeiro, Brazil; $\uparrow$ Office of the Global AIDS Coordinator, US Department of State, Washington DC; \#Cepheid, Sunnyvale, California; **Eunice Kennedy Shriver National Institute of Child Health and Human Development, National Institutes of Health, Bethesda, Maryland; $\dagger+$ Hospital Geral de Nova Iguaçu, DST/AIDS, Nova Iguaçu, Rio de Janeiro, Brazil; $₫+$ †Hospital Federal dos Servidores do Estado, Rio de Janeiro, Brazil; §§SAMRC and Perinatal HIV Research Unit, University of Witwatersrand, Cape Town, South Africa; 9 Department of Obstetrics and Gynecology, Stellenbosch University/ Tygerberg Hospital, Cape Town, South Africa; || || Serviço de Infectologia, Hospital Conceicao, Porto Alegre, Rio Grande do Sul, Brazil; ***Hospital Femina, Porto Alegre, Rio Grande do Sul, Brazil; $\dagger+$ Irmandade da Santa Casa de Misericordia de Porto Alegre, Rio Grande do Sul, Brazil; $++\div$ Department of Pediatrics, Federal University of Minas Gerais, Belo Horizonte, Minas Gerais, Brazil; $\S \S \S$ Department of Pediatrics, Ribeirão Preto Medical School, University of São Paulo, São Paulo, Brazil; q $\mid \uparrow$ Foundation for Maternal and Infant Health (FUNDASAMIN), Buenos Aires, Argentina; and || || ||Escola Paulista de MedicinaUniversidade Federal de São Paulo, São Paulo, Brazil.

Clinical Trials Registration Number: NCT00099359.

Preliminary data were presented at the Pediatric Academic Societies Conference and Asian Society for Pediatric Research Joint Meeting in Vancouver, Canada on May 5, 2014. Abstract number 754433. Preliminary data restricted to the Americas cohort were presented at the Centers for Disease Control and Prevention STD Prevention Conference in collaboration with the 15th International Union against Sexually Transmitted Infections (IUSTI) World Congress and 2nd Latin American International Union against Sexually Transmitted Infections (IUSTI-ALACITS) Congress in Atlanta, Georgia, US. on June 12, 2014. Abstract number 34402

The NICHD HPTN 040 study was supported by NICHD Contract \# HHSN267200800001C (NICHD Control \# N01-HD-8-0001) and U01 AI047986 (Brazilian AIDS Prevention Trials International Network), National Institute of Allergy and Infectious Diseases (NIAID)/NIH. Overall support for Copyright (C) 2016 Wolters Kluwer Health, Inc. All rights reserved.

ISSN: 0891-3668/16/3508-0894

DOI: $10.1097 /$ INF.0000000000001199 the International Maternal Pediatric Adolescent AIDS Clinical Trials Group (IMPAACT) was provided by the National Institute of Allergy and Infectious Diseases (NIAID) of the National Institutes of Health (NIH) under Award Numbers NIAIDU01 AI068632, UM1AI068632 (IMPAACT LOC), UM1AI068616 (IMPAACT SDMC) and UM1AI106716 (IMPAACT LC), with co-funding from the Eunice Kennedy Shriver National Institute of Child Health and Human Development (NICHD) and the National Institute of Mental Health (NIMH (AI068632). In addition, the parent study was supported in part by Boehringer Ingelheim Pharmaceuticals Inc. (BIPI), and GlaxoSmithKline on behalf of ViiV Healthcare. The authors meet criteria for authorship as recommended by the International Committee of Medical Journal Editors (ICMJE) and were fully responsible for all aspects of manuscript development. This particular sub-study was supported by Cepheid, Sunnyvale, CA, where $\mathrm{CT}$ and NG testing of specimens was performed. Support was also provided by the UCLA Center for AIDS Research (CFAR) NIH/ NIAID AI028697. Support for Kristina Adachi's work on this sub-study was also provided in part by the UCLA Children's Discovery and Innovation Institute (CDI). The content, conclusions and opinions expressed in this article are those of the authors and do not necessarily represent those of the National Institutes of Health, the U.S. Department of Health and Human Services, or the U.S. Department of State, affiliated universities, programs or companies of the authors.

Fred Weir, PhD is the Director of Research and Development at Cepheid. David Persing MD, PhD is the Executive Vice President, Chief Medical \& Technology Officer of Cepheid. The other authors have no conflicts of interest to disclose.

Change of Author Affiliations: Lynne Mofenson, MD has retired from service at the Eunice Kennedy Shriver National Institute of Child Health and Human Development, National Institutes of Health, Bethesda, MD. Claire C. Bristow, PhD, MPH, MSc was previously at the UCLA Fielding School of Public Health but is now at UCSD School of Medicine, Division of Global Public Health. D. Heather Watts, MD and George Siberry, MD, MPH were previously at the Eunice Kennedy Shriver National Institute of Child Health and Human Development, National Institutes of Health, Bethesda, MD, U.S., but are currently at the Office of the Global AIDS Coordinator, U.S. Department of State, Washington D.C., U.S.

Address for correspondence: Kristina Adachi, MD, David Geffen School of Medicine at UCLA, Division of Infectious Diseases, Department of Pediatrics, 10833 Le Conte Ave, MDCC 22-442, Los Angeles, CA 90095. E-mail: kadachi@mednet.ucla.edu. 
n 2008, the World Health Organization estimated that 105.7 million new Chlamydia trachomatis (CT) and 106.1 million Neisseria gonorrhoeae $(\mathrm{NG})$ infections occurred worldwide, with highest rates in low- and middle-income countries. ${ }^{1}$ Sexually transmitted infections (STIs) including CT and NG pose additional health risks for HIV-infected pregnant women. Untreated chlamydial and gonococcal infections in pregnancy may lead to fetal loss, premature rupture of membranes and preterm labor and delivery. ${ }^{2-6}$ Maternal chlamydial infections may lead to neonatal conjunctivitis and pneumonia, ${ }^{4}$ whereas gonococcal infections may also predispose infants to conjunctivitis and in rare cases disseminated infections such as sepsis and septic arthritis. ${ }^{3}$

In response to limited published research from low- and middle-income countries of HIV-infected pregnant women with $\mathrm{CT}$ and/or NG infections, the present substudy aimed to assess the health of HIV-exposed infants in the first 6 months of life, particularly in association with these maternal STIs. We, therefore, evaluated adverse infant outcomes associated with these STIs during pregnancy including sepsis, pneumonia, congenital syphilis, septic arthritis, conjunctivitis, death, low birth weight and premature delivery. In a separate report, we described the prevalence of STIs in the National Institute of Child Health and Human Development HIV Prevention Trials Network (NICHD HPTN) 040 cohort and evaluated potential associations between maternal STIs and mother-to-child HIV transmission.?

\section{MATERIALS AND METHODS}

\section{Study Design}

This study was a substudy of the NICHD HPTN 040 trial, also known as International Maternal Pediatric Adolescent AIDS Clinical Trials Network (IMPAACT P1043) NICHD/HPTN 040 (or P1043), a phase 3, triple-arm, randomized, open-label, multicenter study that evaluated the efficacy, safety and tolerance of 3 different infant antiretroviral prophylaxis regimens for the prevention of intrapartum HIV transmission to infants born to HIV-infected pregnant women, who had not received antiretroviral drugs during pregnancy. ${ }^{8}$

Study enrollment consisted of 1684 HIV-infected pregnant women diagnosed with HIV infection at the time of labor and delivery. All women provided written informed consent. Enrollment occurred at multiple sites in Brazil, South Africa, Argentina and the United States. Infants $<32$ weeks of gestational age were excluded from the study.

Maternal plasma HIV RNA levels and CD4+ T-lymphocyte subsets were obtained at the time of labor and delivery. Syphilis testing was performed at the time of labor and delivery using Venereal Disease Research Laboratory test titers with confirmatory treponemal syphilis antibody tests, per standard of care. The primary endpoint of the parent study was HIV infection status at 3 months of age. However, infants were followed until 6 months of age for safety and toxicity monitoring in the parent study. Adverse infant outcome data through age 6 months were collected, which included the variables of interest in this substudy: sepsis, pneumonia, congenital syphilis, septic arthritis, conjunctivitis, death, low birth weight $(<2500 \mathrm{~g})$ and premature delivery $(<37$ weeks and $\geq 32$ weeks).

\section{HIV Diagnosis}

HIV DNA polymerase chain reaction (PCR) was performed on infants within 48 hours of birth and at 10-14 days, 4-6 weeks, 3 months and 6 months of age. Repeat HIV DNA PCR testing was performed to confirm a positive result. Diagnosis of infant HIV infection required 2 positive HIV DNA PCR test (Roche Molecular
Systems Inc., Basel, Switzerland) results collected on different days. During the primary study, infants with a positive HIV DNA PCR test result at birth and positive results on repeat testing were classified as having in utero HIV infection. Infants with a negative HIV DNA PCR result at birth and a positive HIV DNA PCR result on subsequent testing were classified as having intrapartum HIV infection. All HIV-exposed infants enrolled in the study were exclusively formula fed.

\section{Specimen Collection and Chlamydia and Gonorrhea Testing}

Stored maternal urine samples, 1 per patient, collected at the time of labor and delivery or within 48 hours of birth were frozen at $-80^{\circ} \mathrm{C}$ and stored at study sites. Stored urine was thawed, and aliquots $(7 \mathrm{~mL}$ each) were shipped on dry ice for testing at Cepheid, Sunnyvale, CA. Urine samples were tested for the presence of CT and NG using the Xpert CT/NG assay. Results were reported as positive, negative or indeterminate. Indeterminate test results were repeated up to 2 times, and those that remained indeterminate were excluded from data analysis.

\section{Statistical Analysis}

Chi-square (or Fisher exact) test was used to assess the difference in proportions of infants with adverse outcomes, including sepsis, pneumonia, congenital syphilis, septic arthritis, conjunctivitis, death, low birth weight $(<2500 \mathrm{~g})$ and premature delivery $(<37$ weeks), according to maternal STI status (only CT-infected, only NG-infected, CT and NG coinfected or CT and/or NG uninfected) and infant HIV status [HIV-infected (in utero and intrapartum) or HIV-uninfected], respectively. Univariate and multivariate logistic regression modeling (or exact logistic regression as necessary) was used to examine the relationship between adverse clinical outcome and infants born to women with CT and/or NG infection. All computations were done using SAS software v9.3 (Cary, NC).

\section{Human Subjects}

Both the parent trial and the present analysis were approved by the institutional review boards and national ethics committees at each study site.

\section{RESULTS}

Urine samples from $1406 \mathrm{HIV}$-1-infected women were tested for $\mathrm{CT}$ and $\mathrm{NG}$ infections. After excluding 33 indeterminate results ( $2.3 \%$ of samples), 1373 maternal urine test results with linked infant outcomes $(81.5 \%$ of the 1684 women enrolled in the original study) were included in the analysis. Women were from study sites in Brazil (68.3\%), South Africa (29.8\%), Argentina (1.4\%) and the United States $(0.5 \%)$. Further detail on the sociodemographics of our cohort was previously described in our earlier manuscript. ${ }^{7}$ For the 1373 HIV-infected pregnant women included, 249 (18.1\%) had any CT, $63(4.6 \%)$ any NG and $35(2.5 \%)$ had both CT and NG; 277 women $(20.2 \%)$ were positive overall for CT and/or NG. One hundred seventeen $(8.5 \%)$ infants were HIV infected including 75 $(64.1 \%)$ infants infected in utero and 42 (35.9\%) infants infected intrapartum (Fig. 1).

\section{Adverse Infant Outcomes and Maternal Chlamydia and Gonorrhea}

Of 1373 infants, $528(38.5 \%)$ had at least one of the following adverse outcomes (sepsis, pneumonia, congenital syphilis, septic arthritis, conjunctivitis, death, low birth weight or prematurity), and significant differences were noted among infants born to CT- and/or NG-infected women as compared with uninfected 
women $(P=0.001)$. The highest rates of any of those adverse outcomes were noted among infants born to women with both $\mathrm{CT}$ and NG (65.7\%) when compared with those with NG only $(57.1 \%)$, CT only $(39.3 \%)$ and no STI $(37 \%, P=0.001$; Table 1$)$.

In the cohort, $41(3.0 \%)$ infant deaths occurred, and differences in infant death rates were noted among those born to STIinfected and STI-uninfected women $(P=0.02)$. Death rates were highest among infants born to women with CT and NG $(11.4 \%)$ compared with those born to women with NG only $(0 \%)$, CT only $(1.9 \%)$ and CT- or NG-uninfected (3\%) women.

Two hundred forty-four $(17.8 \%)$ of the births resulted in low birth weight infants, whereas $148(10.8 \%)$ infants were born preterm. Significant differences in birth weight $(P=0.001)$ and preterm birth $(P=0.008)$ were observed among infants born to women with and without these STIs. Low birth weight rates were highest among infants born to women with CT and NG (42.9\%) compared with those born to women with NG only $(21.4 \%)$, CT only $(17.8 \%)$ and neither CT nor NG (16.9\%). Similar differences in death and low birth weight rates among these STI groups were noted when infants with congenital syphilis were excluded from the analysis.

Infants born to women with $\mathrm{CT}$ and $\mathrm{NG}$ had the highest rates of preterm delivery: $28.6 \%$ of infants born to women with CT and $\mathrm{NG}$ were born preterm in comparison to $10.2 \%$ of those born to women without CT or NG $(P=0.008)$. Significant differences in infant adverse events were not noted among individual maternal STI groups (CT only, NG only, CT and NG and no CT/NG) for infants with sepsis, pneumonia, congenital syphilis or septic arthritis. The 2 cases of infant conjunctivitis occurred in women with CT.

Among 1373 infants, 117 (8.5\%) were HIV infected. Not surprisingly, differences in rates of any of the adverse events were noted when comparing HIV-infected $(58.1 \%)$ versus HIVuninfected infants $(36.6 \% ; P<0.0001)$. Rates of sepsis $(12 \% \mathrm{vs}$. $3.3 \%, P<0.0001)$, pneumonia $(18.8 \%$ vs. $3.7 \%, P<0.0001)$, congenital syphilis $(10.3 \%$ vs. $5.7 \%, P=0.05)$, death $(13.7 \%$ vs. $2 \%$, $P<0.0001)$ and low birth weight $(25.6 \%$ vs. $17 \%, P=0.02)$ were higher in HIV-infected versus HIV-uninfected infants. Infants who had adverse outcomes (Table 2) and were born to women with CT and/or NG were 3.5 times more likely to be HIV infected [odds ratio (OR): 3.5; 95\% confidence interval (CI): 1.4-8.3] after controlling for maternal syphilis infection. Similar adjusted associations were noted for individual adverse outcomes in infants exposed to maternal CT and/or NG and the likelihood of HIV infection: pneumonia (OR: 4.7; 95\% CI: 1.5-14.9) and death (OR: 6.3; 95\% CI: 1.4-28.1).

In an adjusted multivariate logistic regression controlling for infant HIV-infection status, the risk of any adverse infant outcome
1684 Women Enrolled in NICHD HPTN 040 Parent Study

1406 Maternal Urine Samples Available for Testing (83.5\% of original cohort)
$33(2.3 \%)$ with Indeterminant Results Excluded

1373 Women and Infants Included in Final

Analysis (81.5\% of original cohort)

$1096(79.8 \%)$ No CT or NG

FIGURE 1. Flow chart of subjects enrolled in the present analysis. 
TABLE 1. Adverse Infant Outcomes by Sexually Transmitted Infection Status Among Infants Born to HIV-infected Pregnant Women

\begin{tabular}{|c|c|c|c|c|c|c|}
\hline & $\begin{array}{c}\text { Total } \\
(\mathrm{N}=1373), \mathrm{n}(\%)\end{array}$ & $\begin{array}{c}\mathrm{CT} \text { and } \mathrm{NG} \\
(\mathrm{N}=35), \mathrm{n}(\%)\end{array}$ & $\begin{array}{c}\text { CT Only } \\
(\mathrm{N}=214), \mathrm{n}(\%)\end{array}$ & $\begin{array}{c}\text { NG Only } \\
(\mathrm{N}=28), \mathrm{n}(\%)\end{array}$ & $\begin{array}{c}\text { No STI } \\
(\mathrm{N}=1096), \mathrm{n}(\%)\end{array}$ & $P^{*}$ \\
\hline \multicolumn{7}{|c|}{ Any of the following adverse infant outcomes } \\
\hline No & $845(61.5)$ & $12(34.3)$ & $130(60.8)$ & $12(42.9)$ & $691(63.0)$ & 0.001 \\
\hline Yes & $528(38.5)$ & $23(65.7)$ & $84(39.3)$ & $16(57.1)$ & $405(37.0)$ & \\
\hline \multicolumn{7}{|l|}{ Sepsis } \\
\hline No & $1318(96.0)$ & $33(94.3)$ & $206(96.3)$ & $25(89.3)$ & $1054(96.2)$ & 0.30 \\
\hline Yes & $55(4.0)$ & $2(5.7)$ & $8(3.7)$ & $3(10.7)$ & $42(3.8)$ & \\
\hline \multicolumn{7}{|c|}{ Pneumonia } \\
\hline No & $1305(95.0)$ & $33(94.3)$ & $204(95.3)$ & $24(85.7)$ & $1044(95.3)$ & 0.15 \\
\hline Yes & $68(5.0)$ & $2(5.7)$ & $10(4.7)$ & $4(14.3)$ & $52(4.7)$ & \\
\hline \multicolumn{7}{|c|}{ Congenital syphilis } \\
\hline No & 1289 (93.9) & $32(91.4)$ & $203(94.9)$ & $26(92.9)$ & $1028(93.8)$ & 0.85 \\
\hline Yes & $84(6.1)$ & $3(8.6)$ & $11(5.1)$ & $2(7.1)$ & $68(6.2)$ & \\
\hline \multicolumn{7}{|c|}{ Septic arthritis } \\
\hline No & 1372 (99.9) & $35(100.0)$ & $214(100.0)$ & $28(100.0)$ & 1095 (99.9) & 0.97 \\
\hline Yes & $1(0.1)$ & $0(0.00)$ & $0(0.00)$ & $0(0.00)$ & $1(0.1)$ & \\
\hline \multicolumn{7}{|c|}{ Conjunctivitis } \\
\hline No & 1371 (99.9) & $35(100.0)$ & $212(99.1)$ & $28(100.0)$ & $1096(100.0)$ & 0.01 \\
\hline Yes & $2(0.1)$ & $0(0.00)$ & $2(0.9)$ & $0(0.00)$ & $0(0.00)$ & \\
\hline \multicolumn{7}{|l|}{ Death } \\
\hline No & $1332(97.0)$ & $31(88.6)$ & $210(98.1)$ & $28(100.0)$ & $1063(97.0)$ & 0.02 \\
\hline Yes & $41(3.0)$ & $4(11.4)$ & $4(1.9)$ & $0(0.00)$ & $33(3.0)$ & \\
\hline \multicolumn{7}{|c|}{ Low birth weight } \\
\hline$\geq 2500 \mathrm{~g}$ & $1129(82.2)$ & $20(57.1)$ & $176(82.2)$ & $22(78.6)$ & $911(83.1)$ & 0.001 \\
\hline$<2500 \mathrm{~g}$ & $244(17.8)$ & $15(42.9)$ & $38(17.8)$ & $6(21.4)$ & $185(16.9)$ & \\
\hline \multicolumn{7}{|c|}{ Gestational age } \\
\hline$\geq 37$ wk & $1225(89.2)$ & $25(71.4)$ & $191(89.2)$ & $25(89.3)$ & $984(89.8)$ & 0.008 \\
\hline$<37$ wk & $148(10.8)$ & $10(28.6)$ & $23(10.8)$ & $3(10.7)$ & $112(10.2)$ & \\
\hline
\end{tabular}

*P value calculated using $\chi^{2}$ (or Fisher exact) test between groups.

(eg, including sepsis, pneumonia, low birth weight, prematurity and/ or death) in infants born to mothers with CT, NG or both was 1.35 (OR: 1.35; 95\% CI: 1.03-1.76) times more than infants born to mothers without any STI. However, no associations were noted for individual infant adverse outcomes and those maternal STIs (Table 3).

\section{DISCUSSION}

We evaluated the association of CT and NG infections with adverse infant outcomes. We found that infants born to HIVinfected women with CT and/or NG infection were more likely to have an adverse event through age 6 months when compared with infants born to HIV-infected women without these STIs. In our stratified analysis, the differences for death, low birth weight and preterm delivery were most pronounced for those infants born to women with dual CT and NG infection.

Death in the first 6 months of life occurred in $11.4 \%$ of HIVexposed infants born to women with $\mathrm{CT}$ and NG dual infection, but there was no mortality difference for those with only CT or only NG infections when compared with infants of mothers without either infection. Congenital syphilis and HIV infection are known risk factors for infant death; however, these differences for CT and NG coinfection persisted even after controlling for these confounders. $^{9-11}$ Although limited, the few other existing published studies have also suggested that STIs such as CT or NG during pregnancy may be associated with increased rates of neonatal and infant death. ${ }^{6,12-15}$ One prior study found that stillbirth or neonatal death occurred 10 times more often among CT-infected women than uninfected matched controls. ${ }^{13}$ Another study, which found reductions in neonatal death with presumptive STI treatment for Trichomonas vaginalis, bacterial vaginosis, $\mathrm{CT}$ and $\mathrm{NG}$ in pregnancy, also provides some support for the causal association of maternal STIs in pregnancy and increased neonatal death. ${ }^{16}$
Preterm birth and low birth weight have been attributed to many different risk factors. ${ }^{17,18}$ It is likely that the women in our cohort had some degree of baseline risk for these types of outcomes, particularly given self-reports of high rates of prior preterm birth, usage of alcohol, tobacco and illegal substances and lack of prenatal care as discussed in our prior analysis. ${ }^{7}$ Nevertheless, our study provides additional support for the deleterious role of STIs and adverse birth outcomes such as preterm birth and low birth weight. These findings were particularly striking among the women infected with both CT and NG, where $42.9 \%$ delivered low birth weight infants and $28.6 \%$ had premature infants. These coinfected women also delivered infants with average birth weights that were $358.2 \mathrm{~g}$ less than women uninfected with either of these STIs. Several studies apart from ours have previously suggested that STIs in pregnancy such as CT and/or NG may also be linked with delivery of low birth weight and/or premature infants. ${ }^{6,16,19-24}$ However, studies that have focused on treatment of genital infections and/or chorioamnionitis have reported conflicting results with respect to improvement in birth outcomes with these interventions. ${ }^{6,16,19,24-29}$

HIV infection during pregnancy, particularly in women with lower CD4 T-cell counts, higher serum HIV viral loads and higher placental HIV viral loads, have also all been associated with an increased prevalence of low birth weight and/or premature infants. ${ }^{30-33}$ Yet, our stratified analysis findings demonstrating that women with STIs had higher rates of low birth weight and premature infants remained, even after controlling for infant HIV status. Those findings were also not explained by high rates of untreated maternal syphilis (10\%), as they persisted in a second analysis controlling for this variable. ${ }^{34}$

In fact, our findings may actually underestimate the extent of this problem because very low birth weight and early premature infants were unable to be included; gestational age of $\geq 32$ weeks was required for enrollment in the parent study. 
TABLE 2. Relationship of Infant HIV Infection Status With Adverse Infant Outcomes Among Infants Born to HIV-infected Women With Any Sexually Transmitted Infection (CT/NG Including CT and NG Coinfection)

\begin{tabular}{|c|c|c|c|c|c|c|c|}
\hline & \multirow{2}{*}{$\begin{array}{c}\text { Total } \\
(\mathrm{N}=277) \\
\mathrm{n}(\operatorname{col} \%)\end{array}$} & \multirow{2}{*}{$\begin{array}{l}\text { HIV infected } \\
(\mathrm{N}=28), \\
\mathrm{n}(\text { row } \%)\end{array}$} & \multirow{2}{*}{$\begin{array}{l}\text { HIV uninfected } \\
(\mathrm{N}=249) \\
\mathrm{n}(\text { row } \%)\end{array}$} & \multicolumn{2}{|l|}{ Unadjusted } & \multicolumn{2}{|c|}{ Adjusted* } \\
\hline & & & & OR $(95 \% \mathrm{CI})$ & $P$ & $\mathrm{OR}(95 \% \mathrm{CI})$ & $P$ \\
\hline \multicolumn{8}{|c|}{ Any of the following adverse infant outcomes } \\
\hline No & $154(55.6)$ & $8(5.2)$ & $146(94.8)$ & 1.00 & \multirow[t]{2}{*}{0.004} & 1.00 & \multirow[t]{2}{*}{0.006} \\
\hline Yes & $123(44.4)$ & $20(16.3)$ & $103(83.7)$ & $3.54(1.50-8.36)$ & & $3.45(1.43-8.31)$ & \\
\hline \multicolumn{8}{|l|}{ Sepsis } \\
\hline No & $264(95.3)$ & $26(9.8)$ & $238(90.2)$ & 1.00 & \multirow[t]{2}{*}{0.52} & 1.00 & \multirow[t]{2}{*}{0.60} \\
\hline Yes & $13(4.7)$ & $2(15.4)$ & $11(84.6)$ & $1.66(0.35-7.92)$ & & $1.52(0.31-7.40)$ & \\
\hline \multicolumn{8}{|c|}{ Pneumonia } \\
\hline No & $261(94.2)$ & $23(8.8)$ & $238(91.2)$ & 1.00 & \multirow{2}{*}{0.008} & 1.00 & \multirow{2}{*}{0.008} \\
\hline Yes & $16(5.8)$ & $5(31.3)$ & $11(68.8)$ & $4.70(1.50-14.72)$ & & $4.74(1.51-14.90)$ & \\
\hline \multicolumn{8}{|c|}{ Congenital syphilis } \\
\hline No & $261(94.2)$ & $25(9.6)$ & $236(90.4)$ & 1.00 & \multirow[t]{2}{*}{0.25} & & \\
\hline Yes & $16(5.8)$ & $3(18.8)$ & $13(81.3)$ & $2.18(0.58-8.17)$ & & & \\
\hline \multicolumn{8}{|c|}{ Septic arthritis } \\
\hline No & $277(100)$ & $28(10.1)$ & $249(89.9)$ & & & & \\
\hline Yes & $0(0.0)$ & $0(0.0)$ & $0(0.0)$ & & & & \\
\hline \multicolumn{8}{|c|}{ Conjunctivitis } \\
\hline No & $275(99.3)$ & $28(10.2)$ & 247 (89.8) & 1.00 & \multirow[t]{2}{*}{1.0} & 1.00 & \multirow[t]{2}{*}{1.0} \\
\hline Yes & $2(0.7)$ & $0(0.0)$ & $2(100)$ & $3.69(0-31.24)$ & & $3.92(0-33.21)$ & \\
\hline \multicolumn{8}{|l|}{ Death } \\
\hline No & $269(97.1)$ & $25(9.3)$ & $244(90.7)$ & 1.00 & \multirow{2}{*}{0.02} & 1.00 & \multirow{2}{*}{0.016} \\
\hline Yes & $8(2.9)$ & $3(37.5)$ & $5(62.5)$ & $5.86(1.32-25.97)$ & & $6.30(1.41-28.14)$ & \\
\hline \multicolumn{8}{|c|}{ Low birth weight } \\
\hline$\geq 2500 \mathrm{~g}$ & $218(78.7)$ & $22(10.1)$ & $196(89.9)$ & 1.00 & \multirow[t]{2}{*}{0.99} & 1.00 & \multirow[t]{2}{*}{0.92} \\
\hline$<2500 \mathrm{~g}$ & $59(21.3)$ & $6(10.2)$ & $53(89.8)$ & $1.01(0.39-2.61)$ & & $0.95(0.36-2.50)$ & \\
\hline \multicolumn{8}{|c|}{ Gestational age } \\
\hline$\geq 37$ wk & $241(87.0)$ & $22(9.1)$ & $219(90.9)$ & 1.00 & \multirow[t]{2}{*}{0.17} & 1.00 & \multirow[t]{2}{*}{0.15} \\
\hline$<37$ wk & $36(13.0)$ & $6(16.7)$ & $30(83.3)$ & $1.99(0.75-5.30)$ & & $2.08(0.77-5.57)$ & \\
\hline
\end{tabular}

OR calculated by univariate or exact logistic regression as necessary.

*Each adverse infant outcome was adjusted for maternal syphilis status using multivariable logistic regression.

TABLE 3. Relationship of CT/NG With Adverse Infant Outcomes With/Without Adjusting for Infant HIV Infection Status

\begin{tabular}{lllll}
\hline \hline & \multicolumn{2}{c}{$\begin{array}{c}\text { Unadjusted } \\
\text { (Predictor = Any CT/NG) }\end{array}$} & & $\begin{array}{c}\text { After Adjusting for HIV status } \\
\text { (Predictor = Any CT/NG + HIV Status) }\end{array}$ \\
\cline { 2 - 3 } Adverse Infant Outcomes & OR (95\% CI) & $P$ & & OR (95\% CI) \\
\hline Any adverse infant outcomes (yes) & $1.36(1.04-1.78)$ & 0.02 & & $1.35(1.03-1.76)$ \\
Sepsis (yes) & $1.24(0.65-2.34)$ & 0.51 & & $1.19(0.62-2.26)$ \\
Pneumonia (yes) & $1.23(0.69-2.19)$ & 0.48 & & $1.16(0.65-2.10)$ \\
Low birth weight <2500 g & $1.33(0.96-1.85)$ & 0.086 & & $1.32(0.95-1.83)$ \\
Gestational age $<37$ wk & $1.31(0.88-1.96)$ & 0.18 & & $0.31(0.87-1.95)$ \\
Death (yes) & $0.96(0.44-2.10)$ & 0.91 & & $0.88(0.40-1.96)$ \\
\hline
\end{tabular}

In our evaluation of the effect of chlamydial and gonococcal infections during pregnancy and adverse events among a cohort of HIV-exposed infants, it may not be surprising that we found high overall rates of adverse outcomes and also significant differences in adverse outcome rates when comparing HIVinfected and HIV-uninfected infants..$^{31,32,35-42}$ Existing research on HIV-exposed infants has suggested that HIV exposure alone may be a risk factor for other infections, particularly in infants born to women with advanced HIV infection, due to genital colonization of pathogens, subclinical chorioamnionitis and lower protective antibody titers resulting in decreased transfer of passive immunity across the placenta. ${ }^{43}$ However, while our infant cohort appeared to be at risk for adverse outcomes from HIV exposure at baseline, we still found that infants born to CT- and/or NG-infected mothers were more likely to have an adverse outcome, irrespective of infant HIV infection. In our multivariate logistic regression analysis, although risk could not be associated with individual adverse outcomes (likely because of sample size), the risk of any adverse outcome was 1.36 times more likely in infants of women with $\mathrm{CT}$ and/ or NG. When the analysis was adjusted for HIV-infection status, the risk of any adverse outcome remained essentially unchanged (adjusted OR $=1.35$ ).

One limitation of our study was that the sample size to evaluate the impact of STIs on infant outcomes in the first 6 months of life was based on convenience. The ability to detect differences in adverse infant outcomes by maternal STI group may have been limited by the modest sample size, particularly when STI exposures were combined with analysis of the infant HIV status. Furthermore, 
although data were collected on all types of serious adverse events and clinical outcomes that occurred in the parent study, our analysis was limited to adverse infant outcomes that were more frequently reported with $\mathrm{CT}$ and/or NG infections as opposed to other nonspecific adverse outcomes such as respiratory distress, hypoglycemia, neutropenia, thrombocytopenia and gastroenteritis that were not included. These other types of adverse outcomes have been reported in a separate analysis of a cohort of 1000 HIV-exposed uninfected infants in NICHD HPTN $040 .{ }^{44}$

\section{CONCLUSION}

This study provides important information about the potential deleterious effects of untreated maternal STIs such as CT and NG on the well-being of infants born to high-risk groups of HIVinfected women in low- and middle-income countries. The combination of untreated $\mathrm{CT}$ and/or NG infection in pregnancy and HIV exposure appears to increase the likelihood of adverse outcomes in these infants beyond the risk of HIV acquisition. This additional substudy again highlights the potential benefits of prenatal laboratory-based STI screening and treatment programs, particularly for high risk groups such as HIV-infected pregnant women, which may aid in preventing these types of adverse infant outcomes.

\section{ACKNOWLEDGMENTS}

Kristina Adachi drafted the initial substudy design and data analysis, drafted the initial manuscript and revised and approved the final manuscript as submitted. Jeffrey D. Klausner provided oversight for the current substudy design, data analysis, reviewed, revised and approved final manuscript as submitted. Jiahong Xu designed the data collection instruments, organized data entry for the initial study, provided methods for data analysis, confirmed and finalized primary data analysis study results presented in this paper. Bonnie Ank assisted with preparation and coordination of urine samples from study sites to Cepheid, Inc. and provided laboratory support in the US. Claire C. Bristow performed some of the preliminary data analysis, reviewed and revised the manuscript and approved the final manuscript as submitted. Fred Weir provided direct oversight of specimen analysis at Cepheid with the Xpert CT/NG assay. David Persing facilitated specimen analysis at Cepheid. Mariza Morgado provided laboratory support in Brazil for study conduct, specimen storage, transfer of specimens to the US and participated in data analysis. Esau Joao, Jose Henrique Pilotto, Glenda Gray, Gerhard Theron, Breno Santos, Rosana Fonseca, Regis Kreitchmann, Jorge Pinto, Marisa M. Mussi-Pinhata, Mariana Ceriotto, Daisy Machado, Beatriz Grinsztejn and Francisco I. Bastos were responsible for initial study design, patient recruitment and patient care enrolled in this study at sites in Brazil and in South Africa. They also reviewed and revised the manuscript and approved the final manuscript as submitted. D. Heather Watts, Valdilea Veloso, Lynne Mofenson, Yvonne Bryson, George Siberry and Karin Nielsen-Saines supervised the design of the data collection instruments, supervised data collection at all sites, critically reviewed the manuscript and approved the final manuscript as submitted. Dr. Nielsen-Saines was the principal investigator of the parent study as well as this current substudy.

The authors thank the patients and their families who enrolled in this trial. The authors thank two laboratory personnel who conducted all of the urine specimen preparation and shipment, Mary Ann Hausner and Jessica Liu. The authors also thank Marita McDonough and Lauren Petrella from Boehringer Ingelheim Pharmaceuticals and Helen Watson from GlaxoSmithKline (on behalf of ViiV Healthcare) for assistance with the donation of study drugs from their respective companies for the conduct of the parent study.
In addition to the authors, members of the National Institute of Child Health and Human Development HIV Prevention Trials Network 040/PACTG 1043 protocol team include the following: Edgardo Szyld and Silvia Marzo, Buenos Aires-Foundation for Maternal and Infant Health, Argentina; Flavia Faleiro Ferreira and Fabiana Kakehasi, Belo Horizonte-Federal University of Minas Gerais, Brazil; Rita Lira, Porto Alegre-Hospital Nossa Senhora da Conceicao; Carla Franceschini de Fraga Rita Lira, Porto Alegre-Hospital Femina; Debora Fernandes Coelho, Alberto Sanseverino and Luis Carlos Ribeiro, Porto Alegre-Irmandade da Santa Casa de Misericordia de Porto Alegre; M. Leticia Santos Cruz, Ezequias Martins, Jacqueline Anita de Menezes and Luisa Andrea Torres Salgado, Rio de Janeiro-Hospital dos Servidores do Estado; Ana Valeria Cordovil, Andréa Gouveia, Priscila Mazzucanti and Jorge Eurico Ribeiro, Rio de Janeiro-Hospital Geral de Nova Iguaçu; Geraldo Duarte, Adriana Aparecida Tiraboschi Barbaro and Carolina Sales Vieira, Ribeirao Preto-Universidade de Sao Paulo; Regina Succi, Sao Paulo-Universidade Federal de Sao Paulo; Mark Cotton, Jeanne Louw and Elke Maritz, Capetown-Stellenbosch University and Tygerberg Hospital, South Africa; Sarita Lalsab, Shini Legoete, James Alasdair McIntyre and Mandisa Nyati, Johannesburg-Perinatal HIV Research Unit, University of Witwatersrand and Chris Hani Baragwanath Hospital; Allison Agwu, Jean Anderson, Joan Bess, Jonathan Ellen, Todd Noletto and Nancy Hutton, Baltimore-Johns Hopkins University; Carol Delany and Robert M. Lawrence, Gainesville-Shands Hospital; Chas Griggs, Mobeen Rathore, Kathleen Thoma and Michelle Tucker, Jacksonville-University of Florida; Audra Deveikis and Susan Marks, Long Beach-Miller Childrens Hospital; Linda Bettica, James M. Oleske, Newark-University Medical and Dental School of New Jersey; Midnela Acevedo Flores and Elvia Pérez, San Juan City-San Juan City Hospital; Ronaldo I. Moreira, Marilia Santini de Oliveira, Monica Derrico, Valéria Ribeiro and Thiago Torres, FIOTEC (Fundação para o Desenvolvimento Científico e Tecnológico), Oswaldo Cruz Foundation, Rio de Janeiro (FIOCRUZ); Ruth Dickover, University of California-Davis; Mark Mirochnick, Boston University; Margaret Camarca, James Bethel, Emmanuel Aluko, Yolanda Bertucci, Jennifer Bryant, Patty Chen, Barbara Driver, Ruby Duston, Adriana Ferreira, Priya Guyadeen, Sarah Howell, Marsha Johnson, Linda Kaufman, Naomi Leshabane, Lilya Meyerson, Rita Patel, Lubima Petrova, Georgine Price, Susan Raitt, Scott Watson, Yiling Xu and Eunice Yu, Westat, Inc. Other protocol team members included, Jennifer Read and Jack Moye from the Eunice Kennedy Shriver National Institute of Child Health and Human Development and Elizabeth Smith and Sheryl Zwerski from the National Institute of Allergy and Infectious Diseases.

\section{REFERENCES}

1. World Health Organization. Global Incidence and Prevalence of Selected Curable Sexually Transmitted Infections 2008. Geneva, Switzerland: World Health Organization; 2012.

2. Silveira MF, Ghanem KG, Erbelding EJ, et al. Chlamydia trachomatis infection during pregnancy and the risk of preterm birth: a case-control study. Int J STD AIDS. 2009;20:465-469.

3. Woods CR. Gonococcal infections in neonates and young children. Semin Pediatr Infect Dis. 2005;16:258-270.

4. Hammerschlag MR. Chlamydial and gonococcal infections in infants and children. Clin Infect Dis. 2011;53(suppl 3):S99-S102.

5. World Health Organization. Global Strategy for Prevention and Control of Sexually Transmitted Infections: 2006-2105. Geneva, Switzerland: World Health Organization; 2006

6. Silva MJ, Florêncio GL, Gabiatti JR, et al. Perinatal morbidity and mortality associated with chlamydial infection: a meta-analysis study. Braz J Infect Dis. 2011;15:533-539. 
7. Adachi K, Klausner JD, Bristow CC, et al; NICHD HPTN 040 Study Team. Chlamydia and gonorrhea in HIV-infected pregnant women and infant HIV transmission. Sex Transm Dis. 2015;42:554-565.

8. Nielsen-Saines K, Watts DH, Veloso VG, et al; NICHD HPTN 040/PACTG 1043 Protocol Team. Three postpartum antiretroviral regimens to prevent intrapartum HIV infection. N Engl J Med. 2012;366:2368-2379.

9. Gomez GB, Kamb ML, Newman LM, et al. Untreated maternal syphilis and adverse outcomes of pregnancy: a systematic review and meta-analysis. Bull World Health Organ. 2013;91:217-226.

10. Kuznik A, Habib AG, Manabe YC, et al. Estimating the public health burden associated with adverse pregnancy outcomes resulting from syphilis infection across 43 countries in Sub-Saharan Africa. Sex Transm Dis. 2015;42:369-375.

11. Kapogiannis BG, Soe MM, Nesheim SR, et al. Mortality trends in the US perinatal AIDS collaborative transmission study (1986-2004). Clin Infect Dis. 2011;53:1024-1034

12. Gencay M, Koskiniemi M, Saikku P, et al. Chlamydia trachomatis seropositivity during pregnancy is associated with perinatal complications. Clin Infect Dis. 1995;21:424-426.

13. Martin DH, Koutsky L, Eschenbach DA, et al. Prematurity and perinatal mortality in pregnancies complicated by maternal Chlamydia trachomatis infections. JAMA. 1982;247:1585-1588.

14. Panaretto KS, Lee HM, Mitchell MR, et al. Prevalence of sexually transmitted infections in pregnant urban Aboriginal and Torres Strait Islander women in northern Australia. Aust N Z J Obstet Gynaecol. 2006;46:217-224.

15. Bouwhuis SA, Davis MD. Contribution of sexually transmitted diseases and socioeconomic factors to perinatal mortality in rural Ghana. Int J Dermatol. 2004;43:27-30.

16. Gray RH, Wabwire-Mangen F, Kigozi G, et al. Randomized trial of presumptive sexually transmitted disease therapy during pregnancy in Rakai, Uganda. Am J Obstet Gynecol. 2001;185:1209-1217.

17. March of Dimes P, Save the Children, World Health Organization. Born Too Soon: The Global Action Report on Preterm Birth. Geneva, Switzerland: World Health Organization, 2012

18. Lawn JE, Gravett MG, Nunes TM, et al. Global report on preterm birth and stillbirth (1 of 7): definitions, description of the burden and opportunities to improve data. BMC pregnancy and childbirth. 2010;10(suppl 1):S1.

19. Goldenberg RL, Mudenda V, Read JS, et al. HPTN 024 study: histologic chorioamnionitis, antibiotics and adverse infant outcomes in a predominantly HIV-1-infected African population. Am J Obstet Gynecol. 2006;195:1065-1074.

20. Donders GG, Desmyter J, De Wet DH, et al. The association of gonorrhoea and syphilis with premature birth and low birthweight. Genitourin Med. 1993;69:98-101.

21. Andrews WW, Goldenberg RL, Mercer B, et al. The preterm prediction study: association of second-trimester genitourinary chlamydia infection with subsequent spontaneous preterm birth. Am J Obstet Gynecol. 2000;183:662-668.

22. Kovács L, Nagy E, Berbik I, et al. The frequency and the role of Chlamydia trachomatis infection in premature labor. Int J Gynaecol Obstet. 1998;62:47-54.

23. Blas MM, Canchihuaman FA, Alva IE, et al. Pregnancy outcomes in women infected with Chlamydia trachomatis: a population-based cohort study in Washington State. Sex Transm Infect. 2007;83:314-318

24. Goldenberg RL, Mwatha A, Read JS, et al; Hptn024 Team. The HPTN 024 study: the efficacy of antibiotics to prevent chorioamnionitis and preterm birth. Am J Obstet Gynecol. 2006;194:650-661.

25. Martin DH, Eschenbach DA, Cotch MF, et al. Double-blind placebo-controlled treatment trial of Chlamydia trachomatis endocervical infections in pregnant women. Infect Dis Obstet Gynecol. 1997;5:10-17.

26. Cohen I, Veille JC, Calkins BM. Improved pregnancy outcome following successful treatment of chlamydial infection. JAMA. $1990 \cdot 263 \cdot 3160-3163$
27. Ryan GM Jr, Abdella TN, McNeeley SG, et al. Chlamydia trachomatis infection in pregnancy and effect of treatment on outcome. Am J Obstet Gynecol. 1990;162:34-39.

28. McGregor JA, French JI, Richter R, et al. Cervicovaginal microflora and pregnancy outcome: results of a double-blind, placebo-controlled trial of erythromycin treatment. Am J Obstet Gynecol. 1990;163(5 pt 1):1580-1591.

29. Andrews WW, Klebanoff MA, Thom EA, et al. Midpregnancy genitourinary tract infection with Chlamydia trachomatis: association with subsequent preterm delivery in women with bacterial vaginosis and Trichomonas vaginalis. Am J Obstet Gynecol. 2006;194:493-500.

30. Turner AN, Tabbah S, Mwapasa V, et al. Severity of maternal HIV-1 disease is associated with adverse birth outcomes in Malawian women: a cohort study. J Acquir Immune Defic Syndr. 2013;64:392-399.

31. Brocklehurst P, French R. The association between maternal HIV infection and perinatal outcome: a systematic review of the literature and meta-analysis. Br J Obstet Gynaecol. 1998;105:836-848.

32. Kim HY, Kasonde P, Mwiya M, et al. Pregnancy loss and role of infant HIV status on perinatal mortality among HIV-infected women. BMC Pediatr. 2012;12:138.

33. Marazzi MC, Palombi L, Nielsen-Saines K, et al. Extended antenatal use of triple antiretroviral therapy for prevention of mother-to-child transmission of HIV-1 correlates with favorable pregnancy outcomes. AIDS. 2011;25:1611-1618.

34. Yeganeh N, Watts HD, Camarca M, et al; NICHD HPTN 040P1043 Study Team. Syphilis in HIV-infected mothers and infants: results from the NICHD/HPTN 040 study. Pediatr Infect Dis J. 2015;34:e52-e57.

35. Nielsen-Saines K, Komarow L, Cu-Uvin S, et al; ACTG 5190/PACTG 1054 Study Team. Infant outcomes after maternal antiretroviral exposure in resource-limited settings. Pediatrics. 2012;129:e1525-e1532.

36. Owor M, Mwatha A, Donnell D, et al. Long-term follow-up of children in the HIVNET 012 perinatal HIV prevention trial: five-year growth and survival. J Acquir Immune Defic Syndr. 2013;64:464-471.

37. Newell ML, Borja MC, Peckham C; European Collaborative Study. Height, weight, and growth in children born to mothers with HIV-1 infection in Europe. Pediatrics. 2003;111:e52-e60.

38. Chen JY, Ribaudo HJ, Souda S, et al. Highly active antiretroviral therapy and adverse birth outcomes among HIV-infected women in Botswana. J Infect Dis. 2012;206:1695-1705.

39. Brahmbhatt H, Kigozi G, Wabwire-Mangen F, et al. Mortality in HIVinfected and uninfected children of HIV-infected and uninfected mothers in rural Uganda. J Acquir Immune Defic Syndr. 2006;41:504-508.

40. Koyanagi A, Humphrey JH, Ntozini R, et al; ZVITAMBO Study Group Morbidity among human immunodeficiency virus-exposed but uninfected, human immunodeficiency virus-infected, and human immunodeficiency virus-unexposed infants in Zimbabwe before availability of highly active antiretroviral therapy. Pediatr Infect Dis J. 2011;30:45-51.

41. Kourtis AP, Wiener J, Kayira D, et al. Health outcomes of HIV-exposed uninfected African infants. AIDS. 2013;27:749-759.

42. Rollins NC, Coovadia HM, Bland RM, et al. Pregnancy outcomes in HIVinfected and uninfected women in rural and urban South Africa. J Acquir Immune Defic Syndr. 2007;44:321-328.

43. Mussi-Pinhata MM, Freimanis L, Yamamoto AY, et al; National Institute of Child Health and Human Development International Site Development Initiative Perinatal Study Group. Infectious disease morbidity among young HIV-1exposed but uninfected infants in Latin American and Caribbean countries: the National Institute of Child Health and Human Development International Site Development Initiative Perinatal Study. Pediatrics. 2007;119:e694 e704.

44. Nielsen-Saines K, Watts DH, Joao EC, et al; the NICHD HPTN 040/ PACTG 1043 Protocol Team. To formula feed or not: Infectious morbidity, mortality and growth of HIV-exposed, uninfected, formula-fed infants in Brazil and South Africa enrolled in NICHD/HPTN 040/PACTG 1043. 3rd Pediatrics HIV Conference. Rome, Italy. 2011. 